\title{
PUBLICATIONS
}

\section{The Boston Colloquium Lectures on Mathematics}

\author{
Delivered from September 2 to 5, 1903, Before \\ Members of the American Mathematical \\ Society in Connection with the Summer \\ Meeting Held at the Massachugetts \\ Institute of Technology, \\ Boston, Mass.
}

I. Linear Systems of Curves on Algebraic Surfaces.

By Hanry S. White.

II. Forms of Non-Euclidean Space.

By Frederick S. Woods.

III. Selected Topics in the Theory of Divergent Series and of Continued Fractions.

By Edward B. Van Vleck.

Published for the Society by The Macmillan Company, 1905. 8vo, pp. $v+175$. Price, $\$ 2.00$; to members of the Society, $\$ 1.50$. Orders should be addressed to The Macmillan Company, 66 Fifth Avenue, New York, N. Y. 